\title{
Laser beam calibration for wood surface colour treatment
}

\author{
M. Jurek ${ }^{1}$ (1) R. Wagnerová ${ }^{1}$
}

Received: 21 August 2020 / Accepted: 10 April 2021 / Published online: 28 April 2021

(c) The Author(s) 2021

\begin{abstract}
Laser engraving of photographs on wood surfaces is a challenging task. To optimize the outcome and production quality it is necessary to control every aspect of the laser engraving process. Most of the production machines and technologies overall are mainly focused on laser power control. However, with other systems and deeper knowledge of the wood characteristics it is possible to achieve even better quality. This paper deals with enlarging the number of achievable shades of burned wood and its optimization. A calibration system was developed to control colour shades of engraved wood with a combination of laser power and optic focus. With this approach it is possible to widen achievable palette of engraved shades by continuous control of chemical processes of laser and wood interaction. The production is divided into wood burning and wood carbonization by variation of laser beam focus.
\end{abstract}

\section{Introduction}

The laser engraving technology consists in the controlled generation of a focused light beam, the energy of which heats the point of impact on a non-transparent material for a given wavelength. Depending on the beam profile, the amount of energy supplied, the exposure time and the base material, the surface of the material changes with different courses and intensity (Mishra and Yadava 2015). The effects of laser radiation on the surface of the material are manifested only from a certain power and are irreversible (Minami et al. 2002). The most significant changes in the material during engraving are the loss of the material during sublimation (the depth) and the change in the chemical composition of the surface layer (the colour-shade). The ability to predict the intensity of this change in advance is one of the key areas of laser engraving quality control. A number of publications deal with the impact of laser power intensity on the resulting change of an engraved material (Pagano et al. 2009; Eltawahni et al. 2013; Hernández-Castañeda et al. 2011; Martinez-Conde et al. 2017). However, the shade created by the impact of a laser beam on wood does not depend only on the intensity (the power) and the profile

R. Wagnerová

renata.wagnerova@vsb.cz

1 Department of Control Systems and Instrumentation, VSB-Technical University of Ostrava, 70800 Ostrava, Czech Republic of the laser beam (the cross-section). The material itself is used in combination with its surroundings (the air) to create the desired pigmentation (the shade) of the material. It therefore also depends on the type of wood, its temperature (and the ambient temperature), its humidity (and the ambient humidity), hardness and the current chemical composition of the engraved layers (the age of the wood and its surface treatment) (Wang et al. 2013). In addition to this, wood is a natural composite (Bruno 2018) and a living material, and even after its processing it is constantly changing (degrading-decomposing-absorbing or loosing water) (Chen et al. 2014). Wood dimensions can change as well (Kifetew 1996).

Such changes are accelerated by the environmental conditions (Wu 1998). These are mainly humidity, temperature, and the impact of UV radiation on the wood surface (Timar et al. 2016). To achieve optimal quality, it is necessary to have these changes under control. In addition to the impact of UV radiation, which is now standardly dealt with mainly in the storage stages, it is necessary to keep the material in an environment with a constant temperature and humidity during the time of storage and production, which is difficult to achieve in practice. This makes it difficult to estimate in advance the result for each power level of the laser beam, its different focus and the different materials used.

For a system that will be able to fine-tune the intensity of the laser beam, depending on the current properties of the base material and its environment, it is appropriate to use a sensitive and fast (pulse frequency) emitter. Nowadays the 
engraving of photographs into wood is performed mainly on a $\mathrm{CO}_{2}$ laser. $\mathrm{CO}_{2}$ lasers have high power, so they allow high production speeds and material cutting (Martinez-Conde et al. 2017). However, they generate longer wavelengths $(10,600 \mathrm{~nm})$, so they are not as accurate as the diode layers of a visible spectrum $(455 \mathrm{~nm})$ (Rothenbach and Gupta 2012). The use of semiconductor lasers has experienced a huge increase with the use of CD drives (Barletta et al. 2007; Hernández-Castañeda et al. 2011). They find their application here mainly due to their physical dimensions, purchase price and higher safety, which is given by the wavelength and output power. Thanks to the dramatic increase in the power of laser diodes in recent years this emitter is becoming an important piece of technology (Nakamura et al. 2000; Rodrigues et al. 2014). Diode lasers are increasingly appearing in industrial applications (Diaci et al. 2011; Zeni et al. 2003). Moreover, this potential is amplified by the rapid production due to its purchase price. Diode lasers can be power-controlled, and their beams can be focused relatively precisely (Wang et al. 2000). This makes it possible to transfer much finer details to a wood surface and potentially to calibrate minute changes in the material, in the environment and in the ubiquitous wear of the emitter. However, diode lasers still have up to two orders of magnitude lower optical power and thus production is significantly slowed down. A big advantage is their size, which is up to three orders of magnitude smaller. This makes it easier and cheaper to assemble semiconductor lasers into multi-beam systems that can be controlled simultaneously (increasing power) (Rodrigues et al. 2014), or separately (engraving multiline at once). Semiconductor lasers then have the potential to surpass $\mathrm{CO}_{2}$ lasers not only in accuracy, but also in the speed and economy of production for the application of photo engraving onto wood. The factor that ultimately determines them as a more suitable emitter for the production of engraved photographs onto wood, is its higher efficiency and effectiveness (Li 2000) in the calibration of the beam based on the current properties of a material and its environment.

The use of semiconductor lasers is increasing every year and today they are the most widely used type of laser emitter in the world. This is due to a wide range of uses and a significant increase in their maximum power performance in last decades. The total worldwide turnover from the sale of laser emitters in the year 2016 was 10.4 billion dollars (Holton et al. 2017). Of this $45 \%$ belonged just to the sale of semi-conductor lasers (Unlimited, Strategies 2017). The current trend, which is shown in Fig. 1, just suggests that this technology currently has a more promising future in terms of the attractivity of investment in research and development. For the reasons mentioned above, this calibration system design uses semiconductor emitters.

The overall goal of this article is to provide necessary data and method, which widen the number of achievable

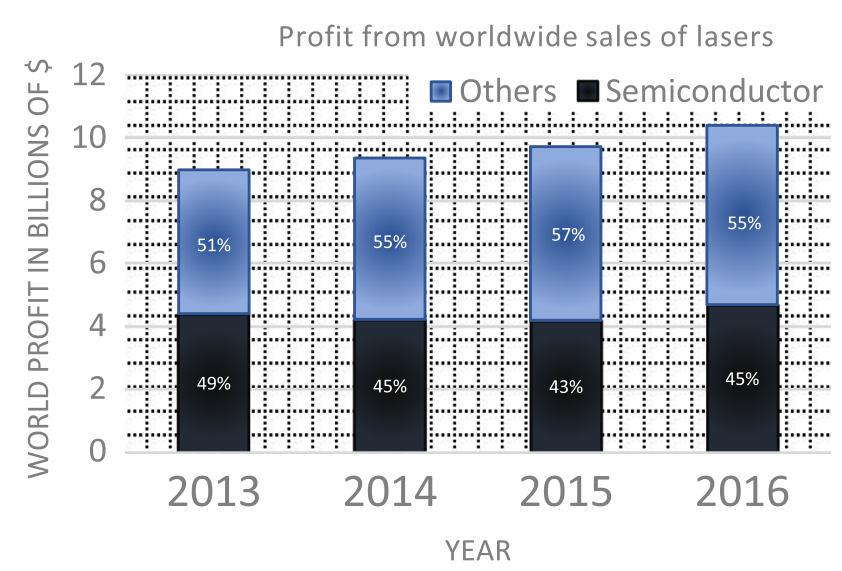

Fig. 1 Semiconductor LASER sales (Holton et al. 2017)

colour shades for laser engraving systems. By conveniently switching between laser burning and laser carbonization, more shades can be produced on a wood surface.

\section{Equipment, materials, and experimental procedures}

This calibration system has been verified by several experiments in the last several years. The experiments were focused on the effects of the impact of a laser beam on a wooden base with different laser beam properties. The essential variables of the laser beam include its intensity, the cross-section of the beam profile (focus) (Leone et al. 2009) and the angle of rotation in respect to the production direction and the direction of the wood growth rings (Silvennoinen et al. 2000; Simonaho et al. 2004). The angle of rotation is important for semiconductor lasers that do not have a circular-beam cross-section, as in the case of $\mathrm{CO}_{2}$ lasers (Zhao et al. 2014). Wood is an inhomogeneous material (Wu and Seltman 1998; Leone et al. 2009). Significant variables of treated wood include its structure (wood species), wood hardness, age, and moisture (Silvennoinen et al. 2000; Hernández-Castañeda et al. 2011).

\subsection{The base material}

Beech veneer samples were selected as testing material for the experiments. The same veneers are used for products of laser engraved photographs on wood by a local start-up company. That is because thin layer of hardwood is easily framed. Beech wood is also one of the most used species for pyrography production (Petru and Lunguleasa 2015). It is widely used because of its convenient properties-lightness, hardness, and availability. The samples had dimensions of $300 \times 200 \mathrm{~mm}$, which roughly correspond to the standard size of A4 paper. A surface sample is shown in 
Fig. 2. The longer dimension is in the direction of the tree growth rings. The veneer has a thickness of $1.4 \mathrm{~mm}$ and is from the central part of a tree (the wood vein). From the engraved side it is sanded with a belt sander with a grit size of P150. The material was dried in an electrical oven. The drying temperature was set to $140{ }^{\circ} \mathrm{C}$ and took $40 \mathrm{~min}$. After drying the samples reduced their size from $300 \times 200 \mathrm{~mm}$ to approximately $299 \times 195 \mathrm{~mm}$. The drying temperature did not exceed $150{ }^{\circ} \mathrm{C}$, at which point polymers in the wood begin to rapidly decompose (Bodirlau et al.2008), which generally darkens the shade of the wood (Kubovský and Kačík 2013). The beech wood used is medium hard with a typical density around $620-720 \mathrm{~kg}$ / $\mathrm{m}^{3}$.

\subsection{The laboratory model}

A standard CNC control system was chosen to control the laser engraving laboratory model. This machine has a working space of $500 \times 500 \mathrm{~mm}$. NEMA17 flange size hybrid stepper motors were used with 2 A stepper motor drivers. The microstepping setting was set to a $1 / 16$ step and the production speed was $2000 \mathrm{~mm} / \mathrm{min}$ for testing. The travels of the machine are designed using HIWIN linear systems with timing belts, which are driven by stepper motors via pulleys. The model structure is derived from a portal 2D CNC plotter. The distance of the laser emitter from the base wood was $40 \mathrm{~mm}$. The working head is designed so that the passing air, which is formed by a strong blower dissipates heat from the laser cooler. Another essential element is the removal of sublimed material from the surface to be treated, which is critical for similar applications (Eltawahni et al. 2013). The model is depicted in Fig. 3.

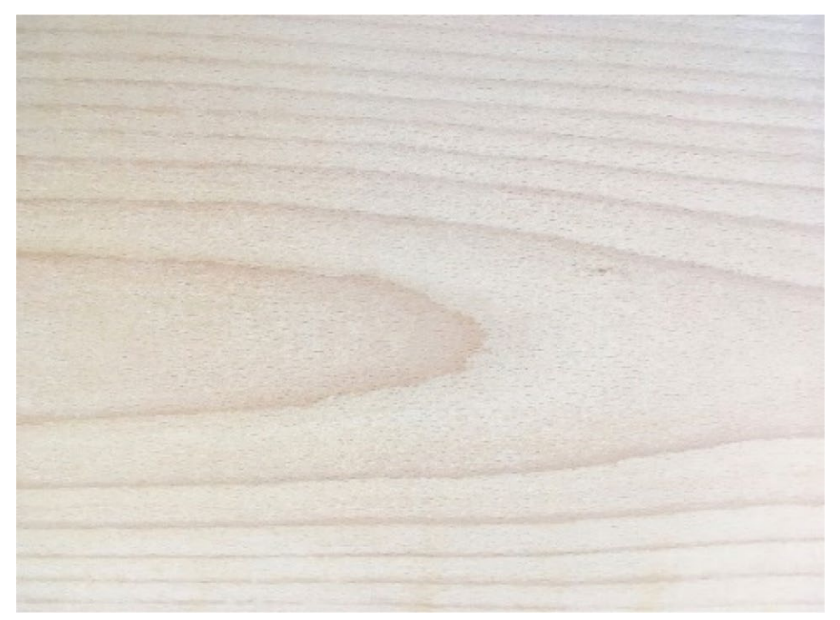

Fig. 2 Beech veneer sample

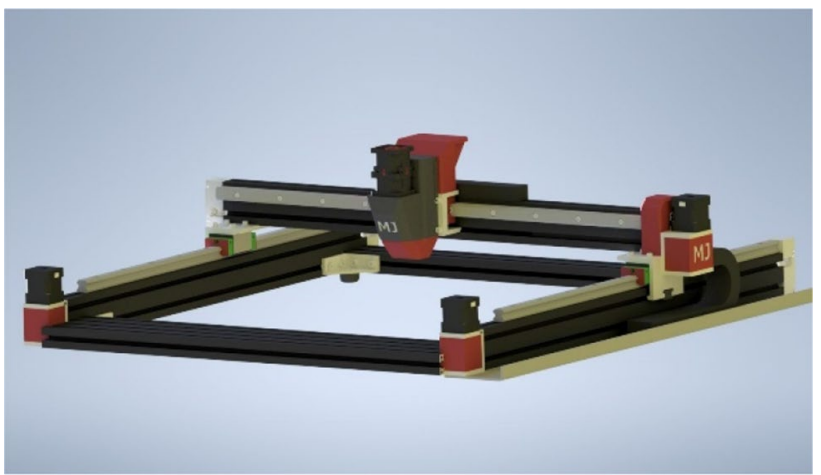

Fig. 3 Model of laboratory stand

\subsection{Semiconductor lasers}

The laser diode used for testing is marked NUBM44-V2 and it is supplied by the Japanese producer of laser diodes NICHIA. It is a $9 \mathrm{~mm}$ multi-mode diode, which provides maximal optical power of $7 \mathrm{~W}$. The power distribution in the laser beam of this diode is illustrated in Fig. 4. This emitter uses gallium nitride $(\mathrm{GaN})$ transition technology to generate a laser beam, which produces a laser with a wavelength of $445 \mathrm{~nm}$. The electronic circuits used to control this emitter were supplied by the Polish company OPT-LASERS. The driver used is modulated via a PWM input and generates power pulses with a frequency at $1 \mathrm{kHz}$. The individual pulses are based on a constant current source and contain several functions to increase the life of the laser diode, such as a soft start, heat protection etc. The diode laser has a rectangular beam profile. There are a number of applications for this beam profile which is more suitable than circular $\mathrm{CO}_{2}$ laser beams (Huaming et al. 2018). One such application is the engraving of photographs into wood.

\subsection{Laser optics}

The output of a semiconductor laser emitter must be adequately focused (Cuccolini et al. 2013; Wang et al. 2000). An aspherical collimating lens, which is made of glass was chosen to focus the laser beam with a wavelength of $455 \mathrm{~nm}$. Its dimensions and other specifications are illustrated in Fig. 5 including the cross-section view. For the type used, with a laser emitter wavelength of $455 \mathrm{~nm}$, the additional

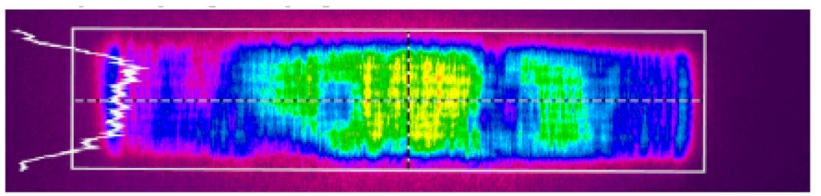

Fig. 4 Semiconductor LASER beam profile 


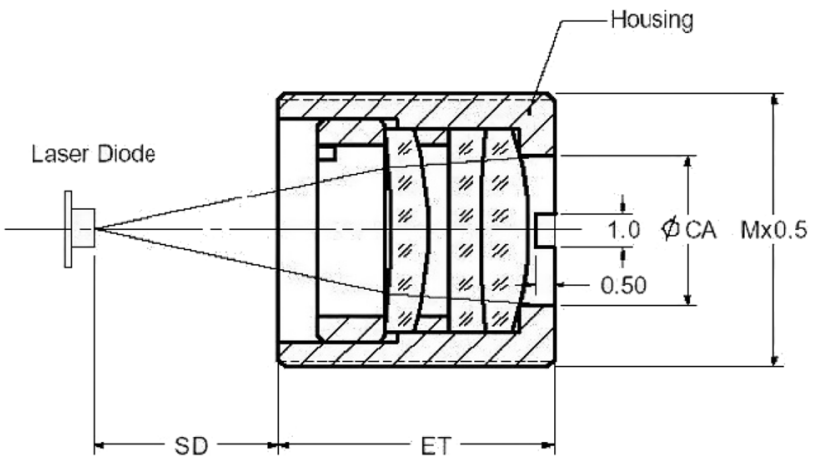

Fig. 5 Three element glass lens

dimensions are as follows. The focal length of the diode (SD) is $3.1 \mathrm{~mm}$, edge thickness is $10 \mathrm{~mm}$ and CA is $5 \mathrm{~mm}$. The diameter of internal thread $\mathrm{M}$ is $9 \mathrm{~mm}$.

\subsection{Power control system}

Pulsed (PWM) power control system controls the power output of a laser diode. The laser driver feeds modulated power signals to the emitter at $1 \mathrm{kHZ}$ frequency. Duty cycle of a signal corresponds to desired power output hence the desired colour shade. Laser drivers often include special signal shaping systems. The most important and most significant from the measurement point of view is a soft start. The typical shape of a laser diode power signal is shown in Fig. 6. Semiconductor components are prone to heat sensitivity. The higher the laser temperature the higher the required current to sustain constant power output. It is important to keep the laser diode actively cooled down to constant temperature. The temperature of the laser housing for these measurements was $20^{\circ} \mathrm{C}$. For this temperature, the laser power properties are listed in Table 1 . The voltage and current are constant for laser beam generation and were set prior to the experiments. The control variable is a duty cycle generated with control
Table 1 Laser power output properties for different power output settings at $20^{\circ} \mathrm{C}$

\begin{tabular}{llll}
\hline $\begin{array}{l}\text { Power set- } \\
\text { ting }(\%)\end{array}$ & $\begin{array}{l}\text { Laser volt- } \\
\text { age }(\mathrm{V})\end{array}$ & $\begin{array}{l}\text { Laser cur- } \\
\text { rent }(\mathrm{A})\end{array}$ & $\begin{array}{l}\text { Optical laser power } \\
{\left[\mathrm{J} \mathrm{s}^{-1}\right] \text { at } 1 \mathrm{kHz} \text { modula- }} \\
\text { tion }\end{array}$ \\
\hline 0 & 0.00 & 0.00 & 0.00 \\
10 & 3.94 & 2.00 & 0.33 \\
20 & 3.94 & 2.00 & 0.65 \\
30 & 3.94 & 2.00 & 0.98 \\
40 & 3.94 & 2.00 & 1.33 \\
50 & 3.94 & 2.00 & 1.65 \\
60 & 3.94 & 2.00 & 1.99 \\
70 & 3.94 & 2.00 & 2.31 \\
80 & 3.94 & 2.00 & 2.63 \\
90 & 3.94 & 2.00 & 2.96 \\
100 & 3.94 & 2.00 & 3.31 \\
\hline
\end{tabular}

system on ATMEGA 328p MCU at $1 \mathrm{kHz}$ and amplified by laser driver.

\subsection{Shade sample}

It is very difficult to describe in detail all factors that affect the range of shades. In the initial phase this work was focused on identifying the most important factor to maximize the number of shades. A shade sample (Fig. 7) was prepared for the measurement, which was to reveal this factor. It contained both sharp transitions and a continuous increase in beam intensity. The intensity change occurred in the sample both in the horizontal and vertical axes. The measurement system was chosen based on initial experience. To improve the calibration of the working head it is appropriate to perform another series of measurements, which is part of the recommendation for further directing the solution. The prepared samples were engraved on a treated piece of beech veneer. Exactly sixteen tests fit on each surface.
Fig. 6 Measurement of laser power control signals at $10 \%$ PWM

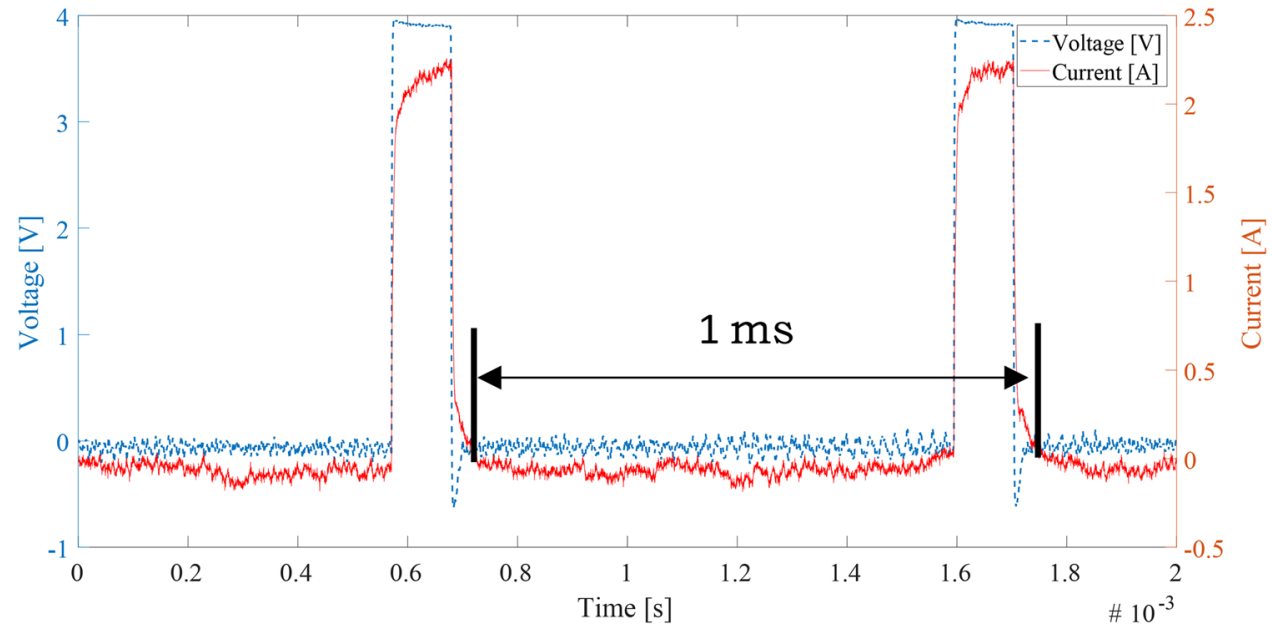


Fig. 7 Grayscale test pattern (right - the graphic used for gcode generation, left-pattern with description of shade values)
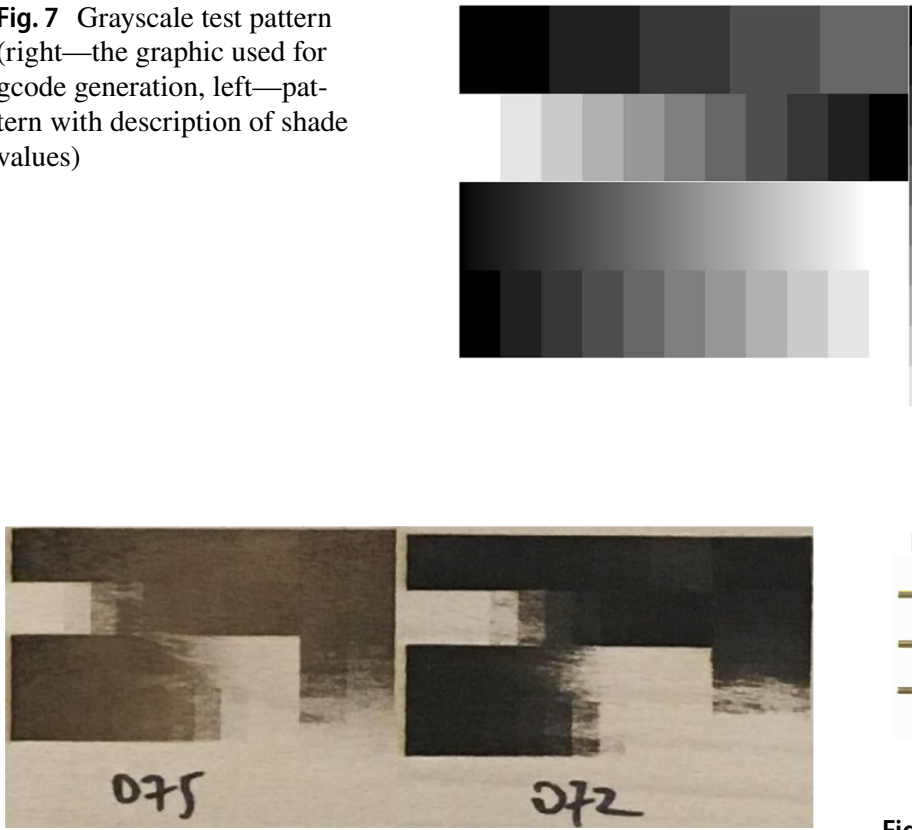
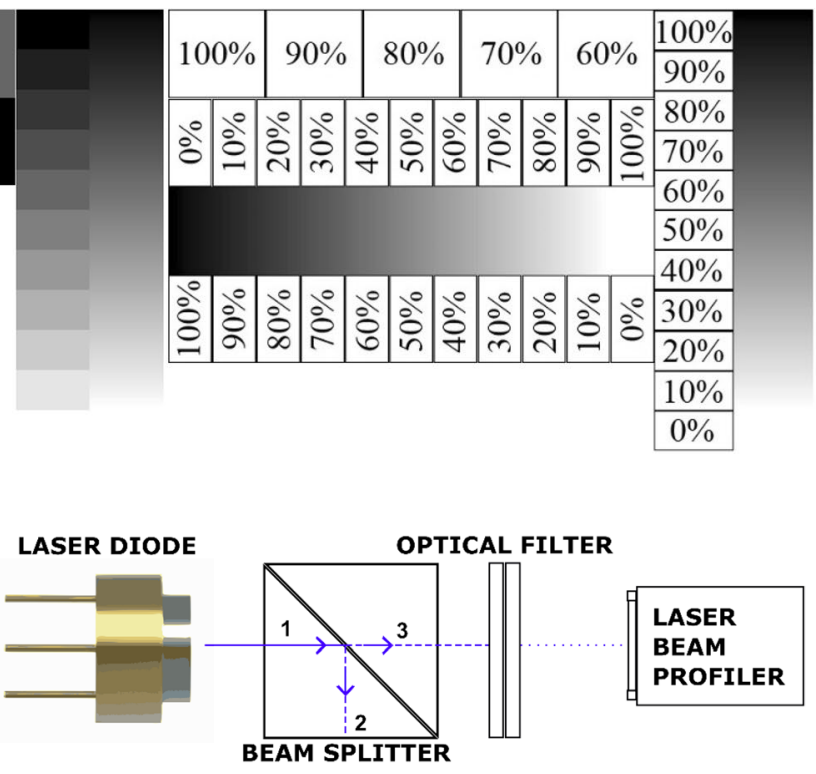

LASER BEAM PROFILER

Fig. 8 Results of focused and defocused LASER

Each test had different production conditions and different surface finishes. A total of ninety-six tests were performed. In terms of the evaluation, a parameter was successfully identified, that led to a fundamental change in the engraved shade. Some parameters were completely ruled out and some require separate and more sensitive measurements.

The parameter that had the greatest impact on the resulting colour of the engraved shade is the beam profile. On the one hand, it is given by the structural design of the emitter, but mostly by the focusing method, which also effects the overall dimensions of the processed point (Eltawahni et al. 2013). The laboratory model that was used for this test contains three series of lenses, that focus the beams on the wood surface. During testing the focus of the beam was fixed, however some tested surfaces were placed on an inclined plane. Thanks to this it was possible to observe the effect of the impact on the focused and defocused beam. This phenomenon is most evident in samples 075 and 072 in Fig. 8. Here it can be seen that the focused beam darkens the wood surface only to a dark brown shade. A typical representative is sample 075 . Due to the variable focus, a slight darkening appeared in the corners. However, the central part of the sample achieves only a dark brown shade. On the contrary, in the case of edge samples, which were further or closer to the focused point of the beam, a further darkening of the points can be very clearly seen (sample 072 ). The reason for these differences is the different beam power density and surface treatment time, which are parameters that play a role in other laser applications (Minami et al. 2002). The primary role of laser engraving is to maximize
Fig. 9 Scheme of laser power characteristics measurement

the number of distinguishable shades. To be able to use both colour scales, it is necessary to divide the calibration sample approximately and to defocus the beam profile for the group of the darkest shades. It is very convenient that the focused beam affects the shade of the wood at lower levels than the defocused beam. This also predetermines it for the lower half of the shades. The upper half of the shades will then be obtained with a defocused beam. Similar systems are already used as autofocus systems (Cao et al. 2018).

To verify the proposed calibration system, the laser beam profile was measured. Thanks to this measurement, the power cross-section of the beam (Fig. 4) and the output characteristics (Fig. 12) of the emitter were obtained. A diagram of this measurement is shown in Fig. 9.

\section{Results and discussion}

The calibration system brings a significant improvement in the production of engraved photographs. The main objective is the number and even distribution of the shades achieved during production. Laser beam shaping by focus control was further examined. All essential data was collected and optimal parameter settings for laser production were calculated.

By changing the beam profile, it is possible to control the chemical processes taking place on the wood surface. The two chemical processes are combustion and carbonization. During the combustion process, the material is considerably heated, it ignites and burns (sublimes) and leaves the surface to be treated in the form of smoke. The beam then "cuts" the depth and removes the material. The shade of the surface treated in this way differs significantly depending on 
the type of wood, and for beech it is a dark brown shade. The other process is carbonization. This is a well-described and well-known process that has been used for a very long time in the production of charcoal, which has several applications on both small and industrial scales (Jesus et al. 2019). Carbonization affects not only the shade of surface but also wood mechanics (Assis et al. 2016). The carbonizing material does not burn and thus the material is not taken away as in the case of combustion (Leone et al. 2009). Organic structures decompose on the surface to be treated, leaving a large amount of black carbon behind (Xu et al. 2017). A surface treated in this way changes colour to a deep black. By combining and controlling these two processes, it is possible to increase the number of shades achieved by laser processing. Each process has its own range of shades. The surface differences in these two treatment methods can be seen in Figs. 10 and 11. Under electron microscope it is visible that defocused laser is causing carbonization on the surface layer of the wood sample. This process leaves a significant number of inorganic compounds (black carbon) which is darkening the resulted colour. By suitably defocusing the beam, it is then possible to freely switch between these two processes, and thus expand the range of achievable shades for engraving photographs into wood even more. Similar dual focus systems are already used in other applications (Mishra and Yadava 2015).

\subsection{Shade dependence on beam power}

The basic input that affects the rate of change on the wood surface during laser engraving, is the power of the laser beam. The power of the laser beam ranges from $\mathrm{mW}$ up to MW depending on the emitter used and targeted application. For wood, engraving powers in the range of tens to hundreds of watts are used for $\mathrm{CO}_{2}$ lasers, and units up to tens of watts for semiconductor lasers. The dependence of the course of the individual shades on the beam power can be divided into three general intervals. The first interval is related to the property of the material (wood) in resisting the effects of laser radiation. This interval is mainly the function of wood humidity, age, density, colour, or light reflectance. The low power levels of the first interval of the laser beam
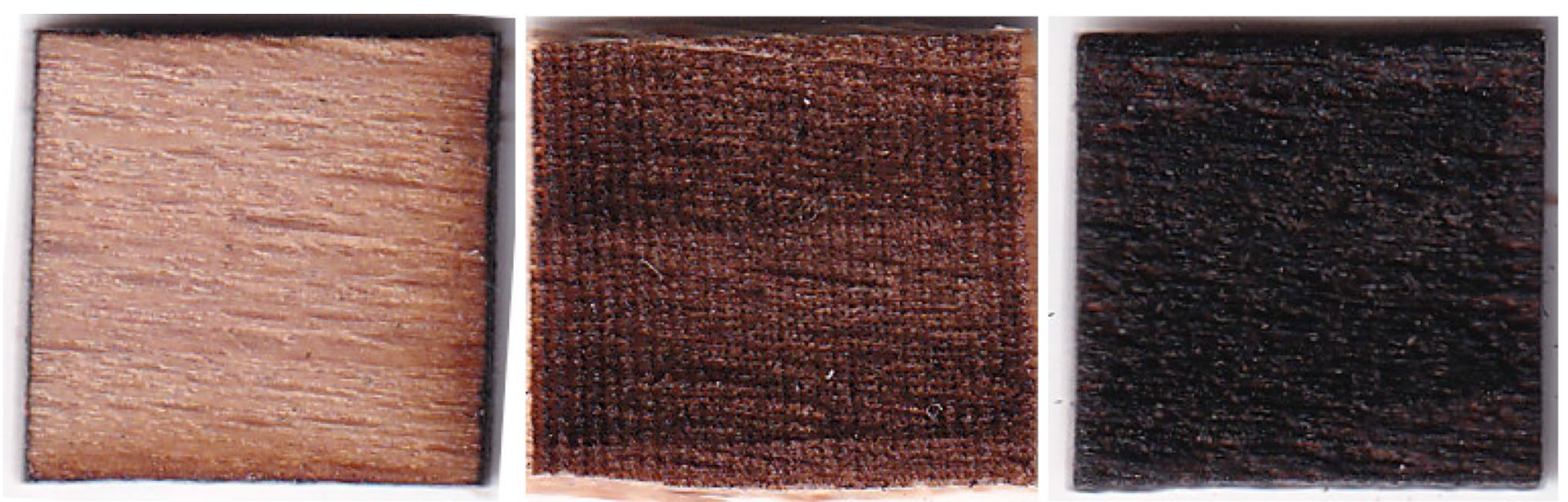

Fig. 10 Surface view of wood samples scanned with electron microscope shown in Fig. 11
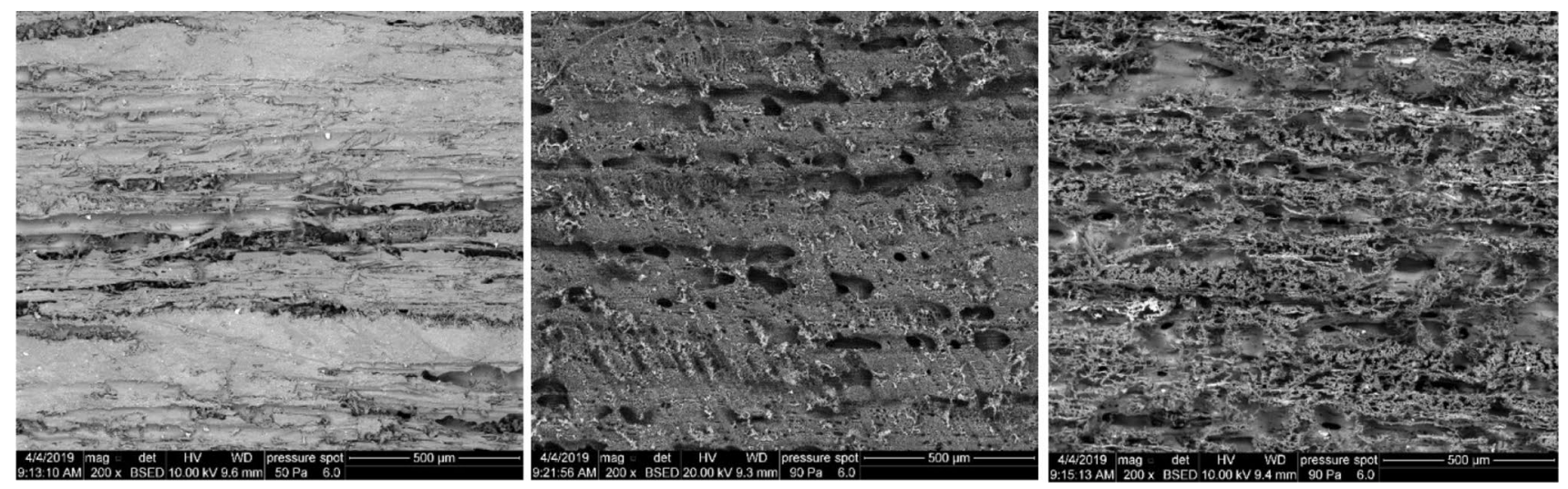

Fig. 11 Electron microscope scan. Left—natural wood surface, middle—burned surface, right—carbonized surface 
do not cause any change on the surface of the wood visible to the human eye. There is only a relatively slight heating of the material within its standard storage conditions. It is important to note that all power intervals discussed in this paragraph will be fundamentally different for each piece of wood, even for samples from a single tree. The second interval is characterized by a sharp change in shade. The heat generated on the surface of the wood exceeds the permissible limit of organic polymers. There is an increasing intensity of carbonization, combustion, and other processes. In the case of wood materials, a point appears in the power characteristic of the emitter at which the rate of wood darkening suddenly decreases with linear power increase. This is because carbonization is affected by heating rate as well as final temperature (Yamashita and Machida 2011). Here is the beginning of the third and last interval of wood shade change by the action of a laser beam. Despite an increase in optical performance, the darkening of the wood surface has only a minimal effect. All these intervals are visible in
Fig. 13. This occurs even though the power characteristic of the semiconductor emitter is very linear, and the emitter thus still supplies the same energy increments. In Fig. 12 the characteristic obtained from measuring the power of the laser beam is shown. The average value and the maximum and minimum of a given measurement are shown. The actual performance characteristic shows a strong linearity and the non-linear elements in the shade characteristic of the burnt wood are thus caused by the physical properties of the base material.

\subsection{Shade dependence on beam focus}

As mentioned above the shade of the burnt wood surface does not only depend on the power of the emitter. It also depends on the beam profile and its cross-sectional power density. Shade dependence on beam power and its focus is shown in Fig. 13. A focused beam has a higher power density, so the wood immediately sublimes (burns), which leads
Fig. 12 Laser power output measurement graph

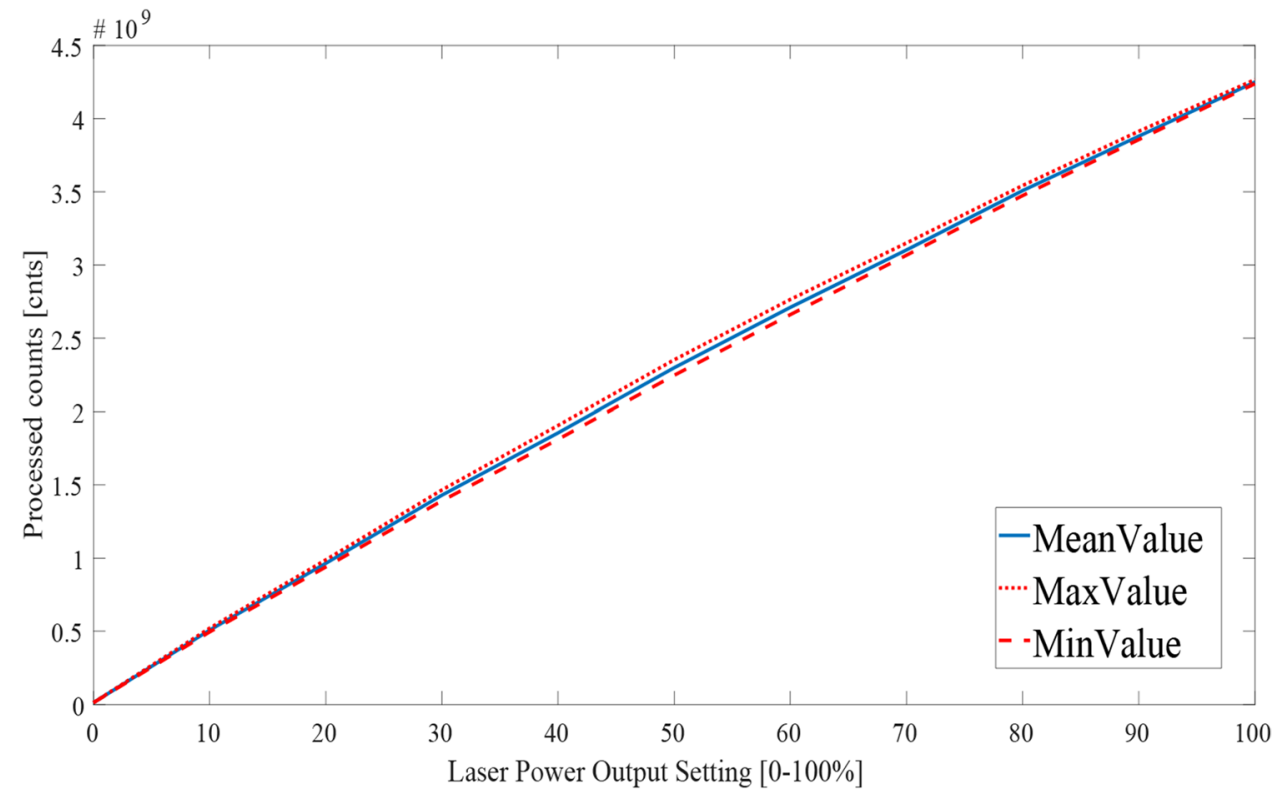

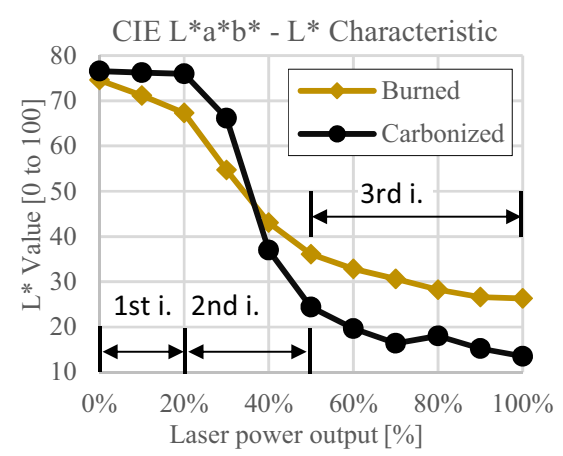
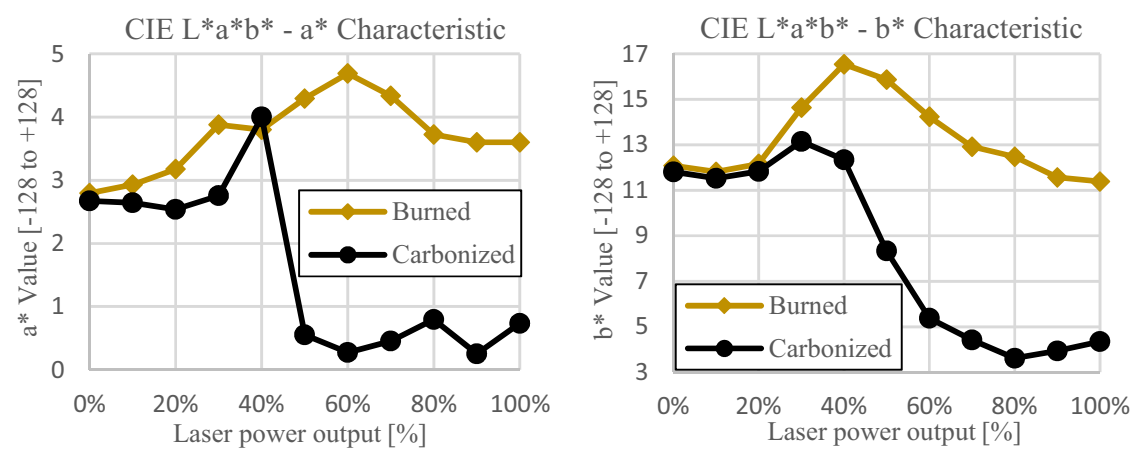

Fig. 13 Wood colour changes with increasing laser power (CIELAB colour space; Left: L*, Middle: a*, Right: $b^{*}$ 
to a sharp loss of material and it darkens to a dark brown colour. Conversely, if the beam is slightly out of focus, its impact profile has a lower power density and acts on the wood for a longer period of time. This creates suitable conditions for starting the carbonization process, in which black carbon is formed on the wood surface and the shade shifts to a deep black colour. To demonstrate this phenomenon, a shade pattern was created, which was engraved on a wood surface which was placed on an inclined plane. The result of burned and carbonized shade change at different power levels is shown in the graph of Fig. 13. The shade components are distributed according to CIELAB colour space. This colour space was selected since the treatment of a wood by laser beam does not only darken the surface but can slightly change its colour tint as well (Vidholdova et al. 2017; Petutschnigg et al. 2013).

It is obvious from measurement that while a major change in surface colour can be observed in lightness $\left(\mathrm{L}^{*}\right)$, there is only a minor change in $\mathrm{b}^{*}$ axis and very small change in $\mathrm{a}^{*}$ axis. It should be noted that results are averages of 10 unique measurements and that wood is inhomogeneous material. That is why, there is considerable potential for measurement error especially for the $\mathrm{a}^{*}$ axis (Table 2 ).

$\mathrm{RE}=\frac{\mid \text { Measured value }- \text { Mean value } \mid}{\text { Mean value }} \cdot 100 \%$

\subsection{Calibration of the power system}

The calibration system's function is to divide the power levels into levels that will be treated by the combustion process and levels that will be treated by surface carbonization.

Table 2 Average of relative errors of measurements

\begin{tabular}{lllr}
\hline Colour characteristic & $\mathrm{L}^{*}(\%)$ & $\mathrm{a}^{*}(\%)$ & $\mathrm{b}^{*}(\%)$ \\
\hline Average error (focused laser) & 3.38 & 10.09 & 5.29 \\
Average error (defocused laser) & 6.01 & 53.26 & 18.64 \\
\hline
\end{tabular}

There usually are 2-3 distinctive laser power output intervals which do not provide visible surface colour changes (Petru and Lunguleasa 2015). The first interval is at the lowest laser power output setting and the second at the highest laser power settings. The highest power output values do not sufficiently change the colour of the wood surface. This is because the power density is very high, and the laser starts depth-cutting the surface instead of just darkening. This high-power output interval is trimmed and replaced with controlled beam defocus values to achieve surface carbonization, and thus further darkening of the engraved point. This principle is illustrated to compare the luminosity of the shade of the surface of charred and carbonized wood (Fig. 14). Laser power and defocus settings are shown in Table 3.

\subsection{Photo engraving results}

The results of the proposed calibration system are shown and compared in Fig. 15. To compare the production quality (number of achieved shades and its distribution), histograms of each result are shown in Fig. 16. The picture shows the fundamental differences in contrast and in the level of detail. This is possible using semiconductor technology to fine tune power and focus between the burnt and carbonized point of the graphic base. Thanks to this, each input photograph can be transferred to any wooden surface with an increased quality of results. It should be noted that the production times of the photographs shown are about thirty minutes for $\mathrm{CO}_{2}$ lasers, while for the semiconductor emitter of the laboratory model it was $3 \mathrm{~h}$. The difference in speed is considerable. Current methods are up to six times faster than the proposed method. This fact is mainly caused by the significantly lower output power of the semiconductor diode that was used. Similar types of diodes have considerable potential to significantly increase the output power in the coming years. The proposed method envisages a threefold acceleration of the production process in the next 2 years. This would soon reduce the speed difference by half. At that moment this proposed method would not only
Fig. 14 Combination of burned and carbonized colour shades

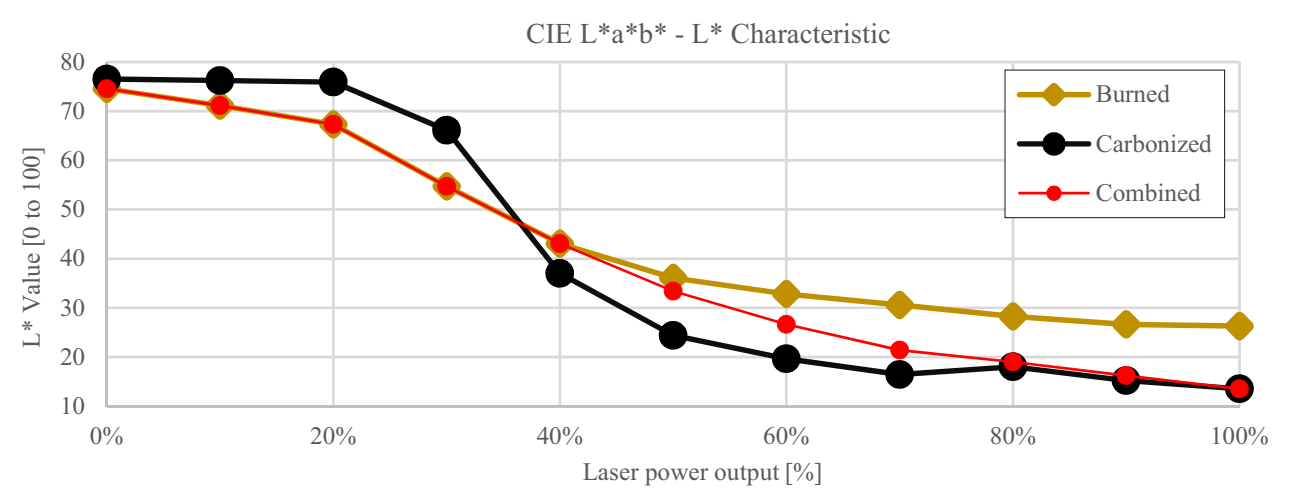


Table 3 Defocus parameters setting for laser control with corresponding shades

\begin{tabular}{llllll}
\hline $\begin{array}{l}\text { Power setting } \\
(\%)\end{array}$ & $\begin{array}{l}\text { Laser voltage } \\
(\mathrm{V})\end{array}$ & $\begin{array}{l}\text { Laser current } \\
(\mathrm{A})\end{array}$ & $\begin{array}{l}\text { Optical laser power per } \\
\text { cycle at } 1 \mathrm{kHz}\left(\mathrm{J} \mathrm{s}^{-1}\right)\end{array}$ & Defocus $(\mathrm{mm})$ & $\begin{array}{l}\text { Engraved } \\
\text { shade [L] }\end{array}$ \\
\hline 0 & 0.00 & 0.00 & 0.00 & 0.00 & 74.57 \\
10 & 3.94 & 2.00 & 0.33 & 0.00 & 71.14 \\
20 & 3.94 & 2.00 & 0.65 & 0.00 & 67.30 \\
30 & 3.94 & 2.00 & 0.98 & 0.00 & 54.72 \\
40 & 3.94 & 2.00 & 1.33 & 0.00 & 43.05 \\
50 & 3.94 & 2.00 & 1.65 & 1.67 & 33.40 \\
60 & 3.94 & 2.00 & 1.99 & 3.34 & 26.64 \\
70 & 3.94 & 2.00 & 2.31 & 5.00 & 21.42 \\
80 & 3.94 & 2.00 & 2.63 & 6.67 & 19.00 \\
90 & 3.94 & 2.00 & 2.96 & 8.34 & 16.22 \\
100 & 3.94 & 2.00 & 3.31 & 10.00 & 13.53 \\
\hline
\end{tabular}
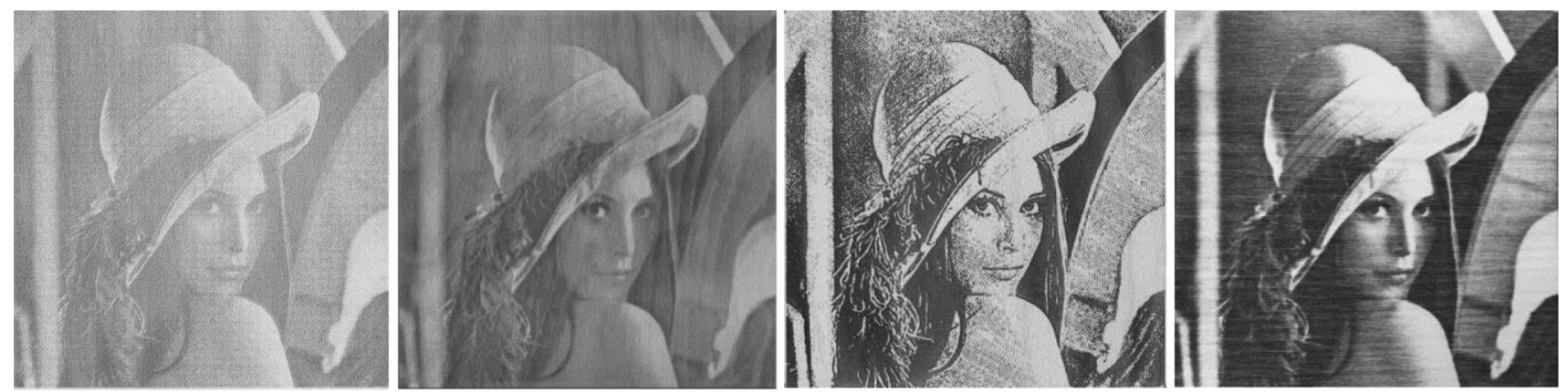

Fig. 15 Comparison of engraved pictures on wood surface. From left: ordered Bayer dithering method; Floyd Steinberg dithering method, Woodener company dithering method and method described in this research

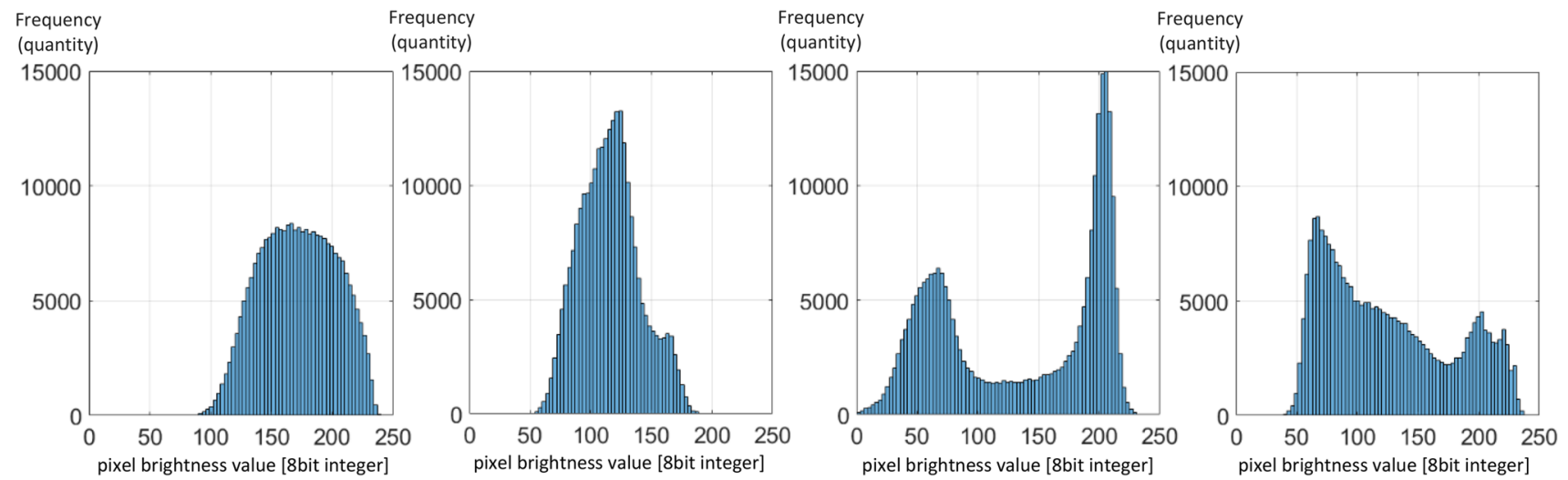

Fig. 16 Histogram comparison of engraved photo results from Fig. 15

provide higher production quality and accuracy compared to the input graphs but would also begin to compete with $\mathrm{CO}_{2}$ lasers in economic fields. This is because semiconductor lasers have significantly higher efficiencies and lower operating costs (Li 2000). Double production time can still mean lower production costs even if the depreciation of the machine is considered. The dimensions of semiconductor technology (Li 2000) are also much more convenient for designing work heads with multiple emitters together. This can compensate for the lower output power and can be produced faster than $\mathrm{CO}_{2}$ lasers.

The higher quality of the transfer of the graphic base to the wood using the above-mentioned calibration system is also evident from the histograms of the results compared in 
Fig. 16. It is obvious that commercial solutions do not reach such a range of individual shades and their even distribution. This is also due to the nature of the input graphics. However, when using a uniform base, the first three histograms contain significant gaps. For the first histogram on the left, the complete absence of dark tones can be observed, which is described by a zero number of scanned pixels for 8-bit values of $0-90$. In this case, the larger third of the histogram is completely missing. The second example is better. However, the dark shades of the surface are in this case achieved by the age of the wood surface. As mentioned in the introduction, wood tends to darken its colour due to degradation of polymers. Freshly cut wood will have significantly lighter colour than older wood samples which were subjected to light, heat, and oxygen for a period of time. Therefore, there are no light shades in this sample. The third example showed an exceptionally wide range of shades for the $\mathrm{CO}_{2}$ laser. One of the reasons was the high firing power, which moved the material to a depth of $1 \mathrm{~mm}$. As a result, there was a higher energy density of the laser beam and a slight defocusing, which caused the carbonization of the wood surface, which began in several places. That is why dark shades appeared in the histogram from the beginning. However, a higher value of the laser beam power makes it more difficult to produce other shades. The entire histogram, and of course, the resulting image is then distributed mainly between two colours. That is between the natural colour of the surface and the colour of an intense laser burning with a constant power. The colour of the natural surface is lighter, as this pattern is made on birch wood instead of beech. The last example is a result of proposed calibration system. Wider distribution of the shades is visible both from the picture and the histogram. The fineness of the semiconductor technology can cause very small darkening differences in the material. In addition to the calibration system and suitable defocusing of the optics, it is possible to achieve very dark values, which are formed by the black carbon of the carbonized surface.

\section{Conclusion}

This contribution was aimed to widen the number of possible colour shades produced by laser for photo engraving techniques. The method of chemical reaction control during wood heating was explored. By switching between wood burning and wood carbonization with beam focus, more colour shades can be obtained. The differences in tint change (CIELAB $\mathrm{a}^{*}$ and CIELAB $\mathrm{b}^{*}$ axes) were especially significant after $1.33 \mathrm{~J} \mathrm{~s}^{-1}$ of laser beam power output. The change in lightness (CIELAB L* axis) can be increased by additional $25 \%$ when using carbonization in laser engraving process. These improvements for laser engraving colour shades are interesting for pyrography works and laser engraving of photographs and graphics on all kinds of wood material. A test sample laser-burned by proposed calibration system was compared to three other samples made by current companies offering laser burned photographs. The main outcome of this improvement is visible in wider distribution of final product's histogram. The number of manufacturable colour shades plays a crucial part in the quality of laser burning technology in case of photographs and shaded graphics. All-important laser setting parameters for beech wood were examined and are provided within this publication.

Acknowledgements This work was supported by the European Regional Development Fund in the Research Centre of Advanced Mechatronic Systems project, CZ.02.1.01/0.0/0.0/16_019/00008 67 within the Operational Programme Research, Development and Education and the project SP2020/57 Research and Development of Advanced Methods in the Area of Machines and Process Control supported by the Ministry of Education, Youth and Sports.

Open Access This article is licensed under a Creative Commons Attribution 4.0 International License, which permits use, sharing, adaptation, distribution and reproduction in any medium or format, as long as you give appropriate credit to the original author(s) and the source, provide a link to the Creative Commons licence, and indicate if changes were made. The images or other third party material in this article are included in the article's Creative Commons licence, unless indicated otherwise in a credit line to the material. If material is not included in the article's Creative Commons licence and your intended use is not permitted by statutory regulation or exceeds the permitted use, you will need to obtain permission directly from the copyright holder. To view a copy of this licence, visit http://creativecommons.org/licenses/by/4.0/.

\section{References}

Assis MR, Brancheriau L, Napoli A, Trugilho PF (2016) Factors affecting the mechanics of carbonized wood. Wood Sci Technol 50(3):519-536. https://doi.org/10.1007/s00226-016-0812-6

Barletta M, Gisario A, Tagliaferri V (2007) Recovering recyclable materials: experimental analysis of CD-R laser processing. Opt Lasers Eng 45(1):208-221. https://doi.org/10.1016/j.optlaseng. 2006.03.013

Bodirlau R, Teaca CA, Spiridon I (2008) Chemical modification of beech wood: effect on thermal stability. BioResources 3(3):789800. https://doi.org/10.15376/biores.3.3.789-800

Bruno L (2018) Mechanical characterization of composite materials by optical techniques: a review. Opt Lasers Eng 104:192-203. https:// doi.org/10.1016/j.optlaseng.2017.06.016

Cao BX, Hoang PL, Ahn S, Kim J-O, Kang H, Noh J (2018) Real-time laser focusing system for high-precision micromachining using diffractive beam sampler and advanced image sensor. Opt Lasers Eng 107:13-20. https://doi.org/10.1016/j.optlaseng.2018.03.002

Chen Y, Tshabalala MA, Gao J, Stark NM, Fan Y (2014) Color and surface chemistry changes of extracted wood. Wood Sci Technol 48:137-150. https://doi.org/10.1007/s00226-013-0582-3

Cuccolini G, Orazia L, Fortunato A (2013) 5 Axes computer aided laser milling. Opt Lasers Eng 51(6):749-760. https://doi.org/10.1016/j. optlaseng.2013.01.015

Diaci J, Bračun D, Gorkič A, Možina J (2011) Rapid and flexible laser marking and engraving of tilted and curved surfaces. Opt Lasers 
Eng 49(2):195-199. https://doi.org/10.1016/j.optlaseng.2010.09. 003

Eltawahni HA, Rossini NS, Dassisti M, Alrashed K, Aldaham TA, Benyounis KY, Olabi A (2013) Evalaution and optimization of laser cutting parametersfor plywood materials. Opt Lasers Eng 51(9):1029-1043. https://doi.org/10.1016/j.optlaseng.2013.02.019

Hernández-Castañeda J, Kursad H, Li L (2011) The effect of moisture content in fibre laser cutting of pine wood. Opt Lasers Eng 49(910):1139-1152. https://doi.org/10.1016/j.optlaseng.2011.05.008

Holton C, Overton G, Nogee A, Belforte D (2017) Annual laser market review \& forecast: where have all the lasers gone? Laser Focus World. https://www.laserfocusworld.com/lasers-sources/article/ 16548135/annual-laser-market-review-forecast-where-have-allthe-lasers-gone. Accessed 20 Jan 2019

Huaming L, Xunpeng Q, Song H, Zeqi H, Mao N (2018) Geometry modeling of single track cladding deposited by high power diode laser with rectangular beam spot. Opt Lasers Eng 100:38-46. https://doi.org/10.1016/j.optlaseng.2017.07.008

Jesus MS, Carneiro AD, Martinez CL, Vital BR, Carneiro AP, Assis MR (2019) Thermal decomposition fundamentals in large-diameter. Wood Sci Technol 53:1353-1372. https://doi.org/10.1007/ s00226-019-01133-9

Kifetew G (1996) Application of the deformation field measurement method to wood during drying. Wood Sci Technol 30:455-462. https://doi.org/10.1007/BF00244440

Kubovský I, Kačík F (2013) Changes of the wood surface colour induced by $\mathrm{CO} 2$ laser and its durability after the xenon lamp exposure. Wood Res 58(4):581-590

Leone C, Lopresto V, Iorio ID (2009) Wood engraving by Q-switched diode-pumped frequency-doubled Nd:YAG green laser. Opt Lasers Eng 47(1):161-168. https://doi.org/10.1016/j.optlaseng. 2008.06.019

Li L (2000) The advances and characteristics of high-power diode laser materials processing. Opt Lasers Eng 34(4-6):231-253. https:// doi.org/10.1016/S0143-8166(00)00066-X

Martinez-Conde A, Krenke T, Frybort S, Müller U (2017) Review: comparative analysis of $\mathrm{CO} 2$ laser and conventional sawing for cutting of lumber and wood-based materials. Wood Sci Technol 51:943-966. https://doi.org/10.1007/s00226-017-0914-9

Minami K, Lawrence J, Li L, Edwards R, Gale A (2002) The removal of industrial epoxy grout using a high-power diode laser. Opt Lasers Eng 38(6):485-498. https://doi.org/10.1016/S01438166(01)00177-4

Mishra S, Yadava V (2015) Laser beam micromachining (LBMM) —a review. Opt Lasers Eng 73:89-122. https://doi.org/10.1016/j.optla seng.2015.03.017

Nakamura S, Pearton S, Fasol G (2000) The blue laser diode-the complete story, 2nd edn. Springer, Berlin

Pagano N, Genna S, Leone C, Lopresto V (2009) Wood Laser machining using CO2 $30 \mathrm{~W}$ laser in CW and pulse regime. In: Teti R (ed) Innovative production machines and systems. LAPT, Napoli, pp $145-150$

Petru A, Lunguleasa A (2015) Effects of the laser power on wood colouration. In: International conference of scientific papers AFASES 2015. 28-30 May, Brasov, pp 1-4

Petutschnigg A, Stöckler M, Steinwendner F, Schnepps J, Gütler H, Blinzer J, Holzer H, Schnabel T (2013) Laser treatment of wood surfaces for Ski cores: an experimental parameter study. Adv Mater SciEng. https://doi.org/10.1155/2013/123085

Rodrigues G, Pencinovsky J, Cuypers M, Duflou JR (2014) Theoretical and experimental aspects of laser cutting with a direct diode laser. Opt Lasers Eng 61:31-38. https://doi.org/10.1016/j.optla seng.2014.04.013

Rothenbach CA, Gupta MC (2012) High resolution, low cost laser lithography using a Blu-ray optical head assembly. Opt Lasers Eng 50(6):900-904. https://doi.org/10.1016/j.optlaseng.2011.12.004

Silvennoinen R, Wahl P, Vidot J (2000) Inspection of orientation of micro fibres in dried wood by a diffractive optical element. Opt Lasers Eng 33(1):29-38. https://doi.org/10.1016/S0143-8166(00) 00025-7

Simonaho S-P, Palviainen J, Tolonen Y, Silvennoinen R (2004) Determination of wood grain direction from laser light scattering pattern. Opt Lasers Eng 41(1):95-103. https://doi.org/10.1016/ S0143-8166(02)00144-6

Timar MC, Varodi AM, Gurau L (2016) Comparative study of photodegradation of six wood. Wood Sci Technol 50:135-163. https:// doi.org/10.1007/s00226-015-0771-3

Unlimited, Strategies (2017) The worldwide market for lasers: market review and forecast 2017. Strategies Unlimited, New Hampshire

Vidholdova Z, Reinprecht L, Igaz R (2017) The impact of laser surface modification of beech wood on its color and occurrence of Molds. BioResources 12(2):4177-4186

Wang S, Tay S, Quan C, Shang H (2000) Collimating of diverging laser diode beam using graded-index optical fiber. Opt Lasers Eng 34(2):121-127. https://doi.org/10.1016/S0143-8166(00)00089-0

Wang Y, Ando K, Hattori N (2013) Changes in the anatomy of surface and liquid uptake. Wood Sci Technol 47:447-455. https://doi.org/ 10.1007/s00226-012-0497-4

Wu R (1998) Microstructural study of sanded and polished wood by replication. Wood Sci Technol 32:247-260

Wu R, Seltman J (1998) Microstructural investigation of UV-laser irradiated pine (Pinussi/vestris I_). Wood Sci Technol 32:183-195

Xu D, Ding T, Li Y, Zhang Y, Wang DZ (2017) Transition characteristics of a carbonized wood cell wall investigated by scanning thermal microscopy (SThM). Wood Sci Technol 51:831-843. https:// doi.org/10.1007/s00226-017-0919-4

Yamashita N, Machida M (2011) Carbonization of bamboo and consecutive low temperature air activation. Wood Sci Technol 45:801-808. https://doi.org/10.1007/s00226-010-0372-0

Zeni L, Campopiano S, Cutolo A, D’Angelo G (2003) Power semiconductor laser diode arrays characterization. Opt Lasers Eng 39(2):203-217. https://doi.org/10.1016/S0143-8166(01)00111-7

Zhao C, Zhang H, Wang Y (2014) Semiconductor laser asymmetry cutting glass with laser induced thermal-crack propagation. Opt Lasers Eng 63:43-52. https://doi.org/10.1016/j.optlaseng.2014. 06.008

Publisher's Note Springer Nature remains neutral with regard to jurisdictional claims in published maps and institutional affiliations. 